\title{
Success of stent-in-stent deployment after intraductal radiofrequency ablation for hepatic hilar obstruction
}

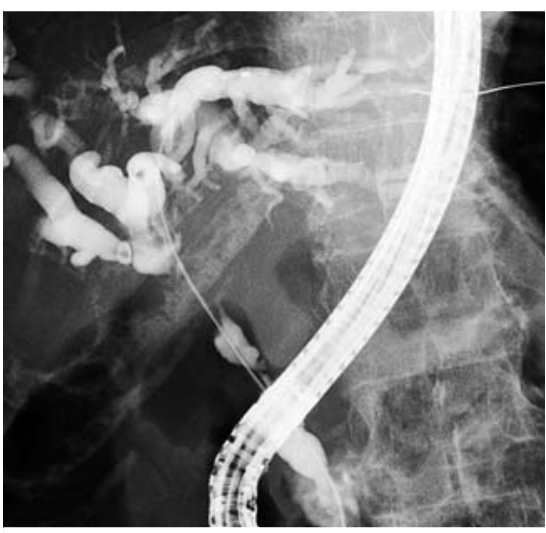

- Fig. 1 Cholangiography revealed hepatic hilar obstruction.

Unresectable malignant hepatic hilar biliary obstruction (MHBO) is often treated by deploying several uncovered self-expandable metal stents (UCSEMS) [1-4]. Bilateral UCSEMS can be deployed using either side-by-side or stent-in-stent (SIS) procedures. However, SIS might not be as widely appropriate for MHBO because the procedure is technically complex. Furthermore, the risk of complications such as focal cholangitis can increase if bilateral SIS deployment fails after contrast medium is injected. However, a recent meta-analysis found that intraductal radiofrequency ablation (RFA) for malignant biliary obstruction might be associated with improved stent patency [5]. Here, we describe bile duct dilation using intraductal RFA to improve the technical success of subsequent UCSEMS deployment using SIS ( Video 1 ).

Computed tomography and endoscopic ultrasound-guided fine-needle aspiration indicated bile duct carcinoma with liver metastasis in a 77-year-old woman with obstructive jaundice. We therefore attempted biliary drainage. The bile duct was cannulated under endoscopic retrograde cholangiopancreatography and contrast medium was injected for cholangiography, which showed hepatic hilar obstruction ( $>$ Fig.1). A cholangioscope

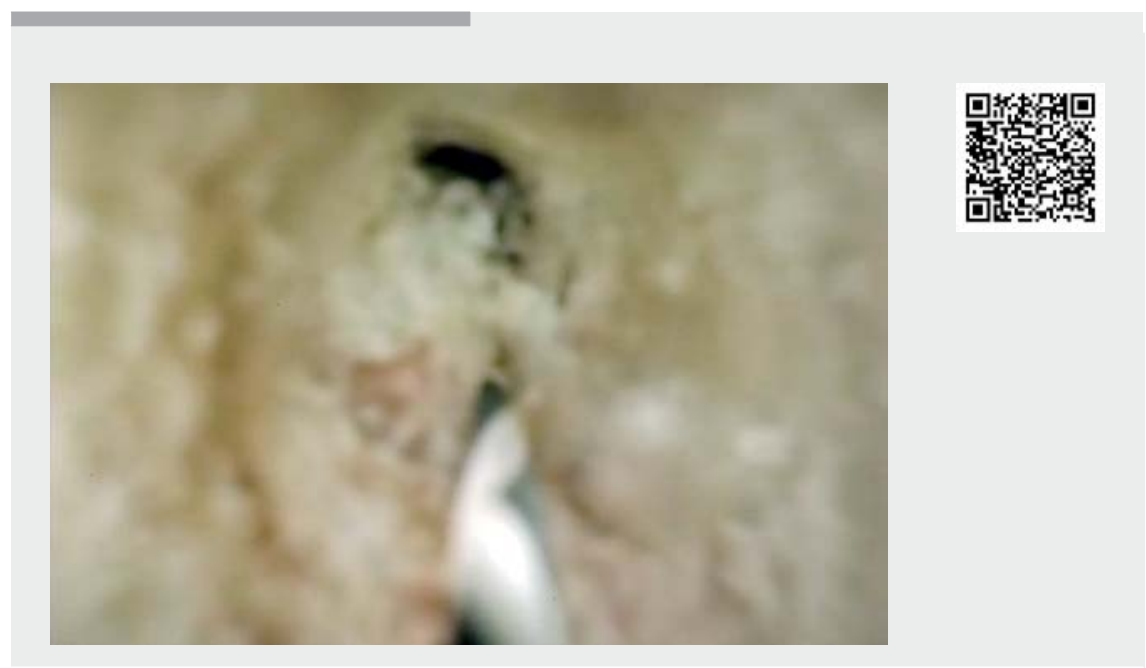

Video 1 Cholangioscopy confirmed that the tumor has disappeared after radiofrequency ablation.
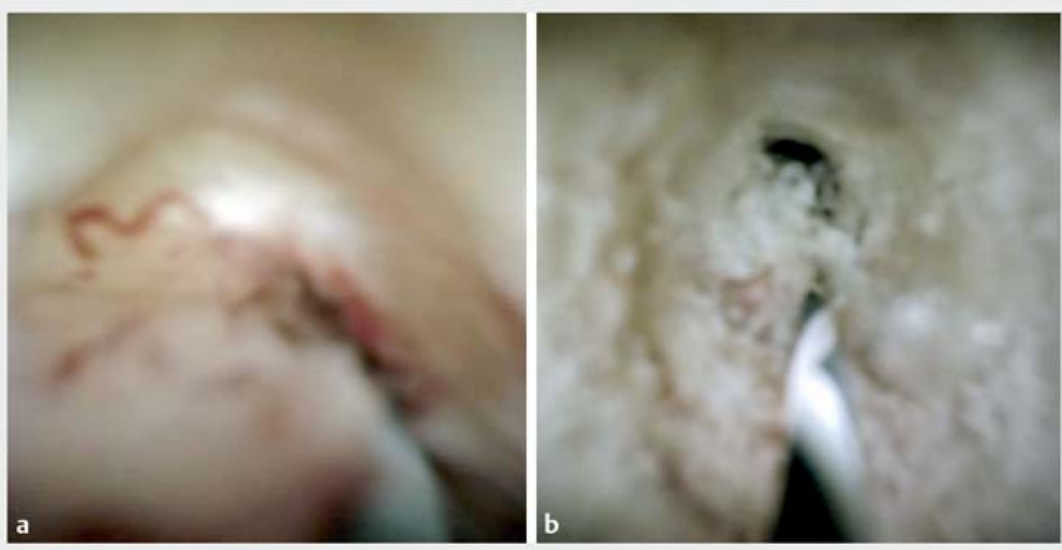

- Fig. 2 Cholangioscopy findings. a A tumor was visible in the bile duct. b The tumor was no longer visible after intraductal radiofrequency ablation.

inserted before intraductal RFA to prevent bile duct perforation revealed a tumor in the bile duct ( $\mathbf{F i g} \mathbf{2} \mathbf{a}$ ). Intraductal RFA (Habib EndoHPB; Boston Scientific, Marlborough, Massachusetts, USA) was then attempted using an RFA generator (VIO 200D; Erbe Elektromedizin $\mathrm{GmbH}$, Tübingen, Germany), supplying electrical energy at $350 \mathrm{kHz}$ (effect 8) and $7 \mathrm{~W}$ for 90 seconds. The effects of RFA were assessed by repeat cholangioscopy of the bile duct, which showed that the tumor had disappeared ( Fig.2b). Because the bile duct was now dilated ( Fig.3a), a UCSEMS (ZEOSTENT V: Zeon Medical Inc., Tokyo, Japan) was easily deployed using the SIS technique without adverse events ( $\triangleright$ Fig. $\mathbf{3} \mathbf{b}$ ). 

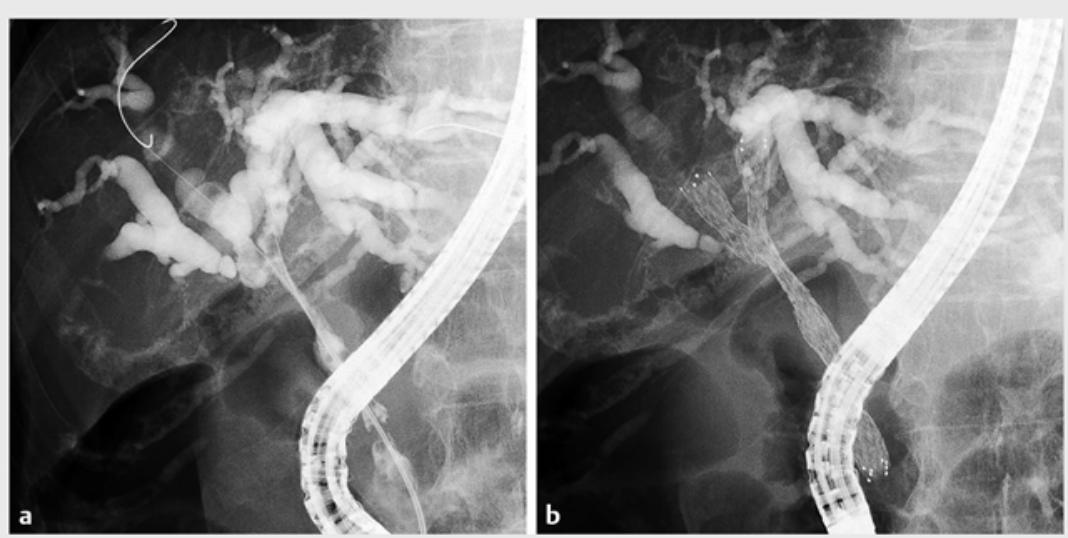

- Fig. 3 Cholangiography views. a The dilated bile duct after radiofrequency ablation. b Deployment of multiple uncovered self-expandable metal stents was easily achieved using the stent-in-stent technique.

Although a prospective randomized trial is needed, intraductal RFA might be useful for dilating the bile duct before deploying stents to treat MHBO.

\section{Endoscopy_UCTN_Code_TTT_1AR_2AF}

\section{Competing interests}

None

The authors

Takeshi Ogura, Saori Ueno, Nobu Nishioka, Masanori Yamada, Kazuhide Higuchi 2nd Department of Internal Medicine, Osaka Medical College, Osaka, Japan

\section{Corresponding author}

\section{Takeshi Ogura, MD}

2nd Department of Internal Medicine, Osaka Medical College, 2-7 Daigakuchou, Takatsukishi, Osaka 569-8686, Japan Fax: +81-72-6846532

oguratakeshi0411@yahoo.co.jp

\section{References}

[1] Sawas T, Al Halabi S, Parsi MA et al. Selfexpandable metal stent versus plastic stents for malignant biliary obstruction: a meta-analysis. Gastrointest Endosc 2015; 82: 256-267.e7

[2] Rerknimitr R, Angsuwatcharakon P, Ratanachu-ek T et al. Asia-Pacific consensus recommendations for endoscopic and interventional management of hilar cholangiocarcinoma. J Gastroenterol Hepatol 2013; 28: 593-607

[3] Yang MJ, Kim JH, Hwang JC et al. Prospective multicenter study of the challenges inherent in using large cell-type stents for bilateral stent-in-stent placement in patients with inoperable malignant biliary obstruction. Gut Liver 2018; 15: 722-727

[4] Chahal P, Baron TH. Expandable metal stents for endoscopic bilateral stent-within-stent placement for malignant hilar biliary obstruction. Gastrointest Endosc 2010; 71: 195-199

[5] Sofi AA, Khan MA, Das A et al. Radiofrequency ablation combined with biliary stent placement versus stent placement alone for malignant biliary stricture: a systematic review and meta-analysis. Gastrointest Endosc 2018; 87: 944-951
Bibliography

DOI https://doi.org/10.1055/a-1067-4213

Published online: 13.12 .2019

Endoscopy 2020; 52: E206-E207

(c) Georg Thieme Verlag KG

Stuttgart · New York

ISSN 0013-726X

\section{ENDOSCOPY E-VIDEOS}

https://eref.thieme.de/e-videos

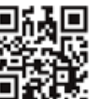

Endoscopy E-Videos is a free access online section, reporting on interesting cases and new

techniques in gastroenterological endoscopy. All papers include a high quality video and all contributions are freely accessible online.

This section has its own submission website at

https://mc.manuscriptcentral.com/e-videos 